\title{
On Abnormal Vibration Generated in Flow Dynamic Conveyor*
}

\author{
Kunihiko ISHIHARA** \\ **Institute of Technology and Science, The University of Tokushima \\ 2-1 Minami-Jyosanjima-Cho, Tokushima-City, Tokushima-Pref. 770-8506, Japan
}

\begin{abstract}
This paper describes a self-excited vibration of a Flow Dynamic Conveyor (FDC). The FDC is often used in power plants and in iron works because of superiority in noise control compared with a roller type conveyor. The FDC consists of a trough and a belt, and the air is supplied from many holes provided on the trough. A large vibration suddenly occurs when the flow rate becomes the critical value. In this paper, some measurements were performed in order to clarify the phenomenon. As a result, it was found that the phenomenon was the self-excited vibration based on the interference between two vibration systems such as the load $\cdot$ air-spring system and the trough $\cdot$ supporting system.
\end{abstract}

Key words: Self-Excited Vibration, Measurement, Material Handling Equipment, Modal Analysis, Coupled Vibration, Stability

\section{Introduction}

The Flow Dynamic Conveyer (FDC hereafter) has been used to convey coal, gypsum and ash in power plants and in iron works. It has often been used due to the superiority in noise control compared with a conventional roller type conveyor. As shown in Fig.1, the FDC mainly consists of a trough and a belt and conveys various loads on a belt floated by air supplied from a number of holes set on the trough. Then the low power and the low noise are achieved. However when the air flows between the belt and the trough, the abnormal vibration is possible to occur in specific a condition (Flow rate, Load). This phenomenon is considered to be the Leakage-Flow -Induced Vibration.

In this field, Inada and Hayama [1,2] studied the fluid dynamic force generated in translation and rotation motions of the one-dimensional tapered leakage channel. These results are useful in understanding the self-excited vibration due to the analytical approach in spite of the existence of assumption. Next, Arai, et al. [3] analyzed the vibration of an axisymmetric body due to the leakage flow. Li et al. [4] studied the flow of the annular leakage. From these works, the leakage-flow induced vibration has been clarified gradually.

Recently, Omori et al. [6,7] studied the stability of the FDC similar to the one presented here. Their papers proposed an analytical method to calculate the critical flow rate at onset of the instability which agrees well with the experimental data.

However there are few examples that the trough has vibrated violently at occurrence of the instability in the real phenomenon. So the objective of this study is to clarify that the abnormal vibration occurred in the FDC is the self excited vibration by using the segment of the real thing and measuring vibrations and pressures.

*Received 27 Nov., 2007 (No. T2-06-0956) Japanese Original : Trans. Jpn. Soc. Mech. Eng., Vol.73, No.729, C (2007),

pp.1279-1284 (Received 12 Sep., 2006) [DOI: 10.1299/jsdd.2.550] 


\section{Experimental Apparatus and Items}

\subsection{Experimental Apparatus}

Fig.1 shows the principle of the FDC. When the air is supplied between the trough (thickness is $9 \mathrm{~mm}$ ) and the belt (thickness is $4 \mathrm{~mm}$ ), the pressure distribution is generated to balance the load on the belt. The clearance changes as the flow rate changes. The mass per unit length of the trough and the belt are $70.6 \mathrm{~kg} / \mathrm{m}$ and $11.4 \mathrm{~kg} / \mathrm{m}$, respectively. The maximum load is $50 \mathrm{~kg} / \mathrm{m}$ and the velocity of the belt is $230 \mathrm{~m} / \mathrm{min}$. But the accelerations and the pressures are measured in condition that the belt is not moved and only air is applied. Fig.2 shows the wire-frame of the model used in this experiment. Two hundred points hit by the impulse hammer are selected and the acceleration at point $\mathrm{A}$ is measured.

Fig.3 (a) and Fig.3 (b) show pictures of experimental apparatus of FDC. Fig.3 (a) is a bird's eye view and Fig. 3 (b) is a looking at FDC from underneath.

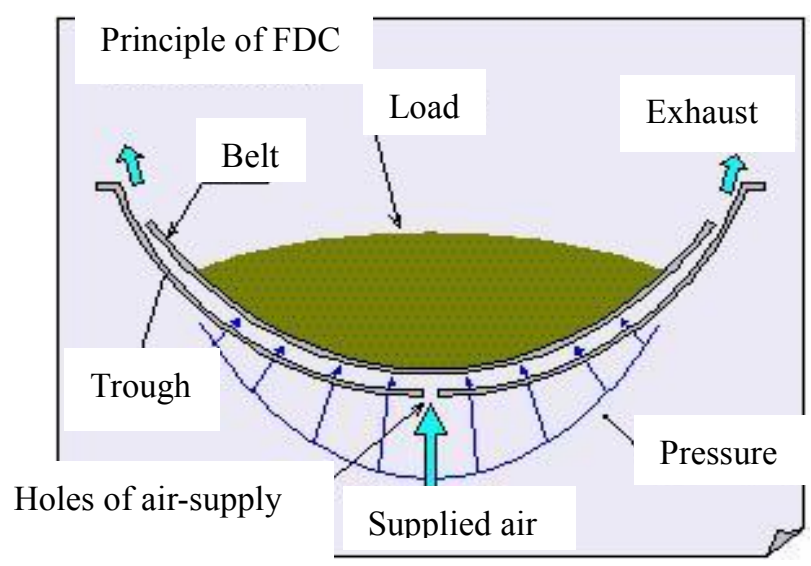

Fig.1 Cross section of FDC

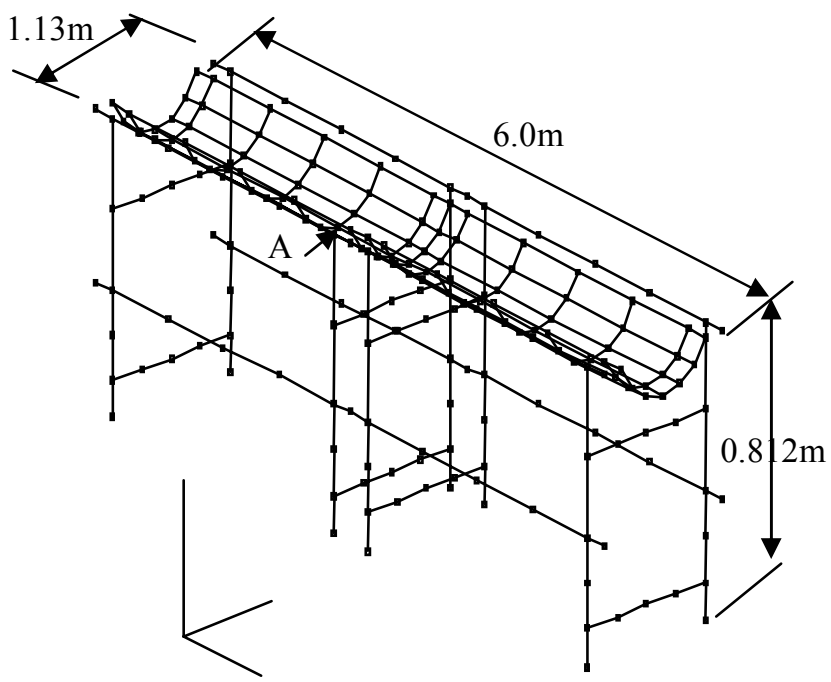

Fig.2 Wire frame of experimental apparatus 


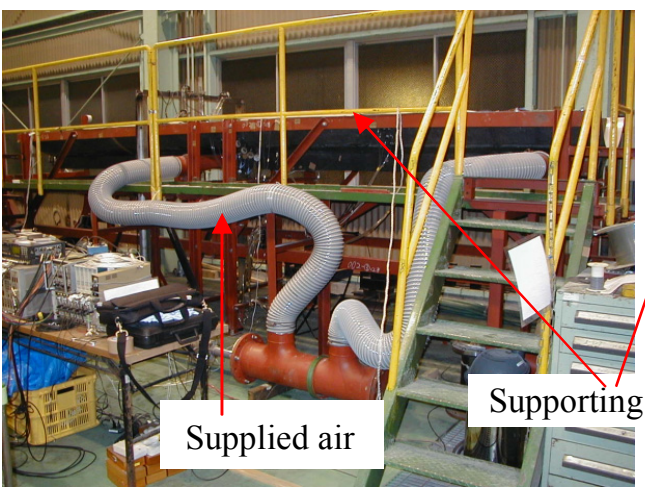

(a) Bird's eye view

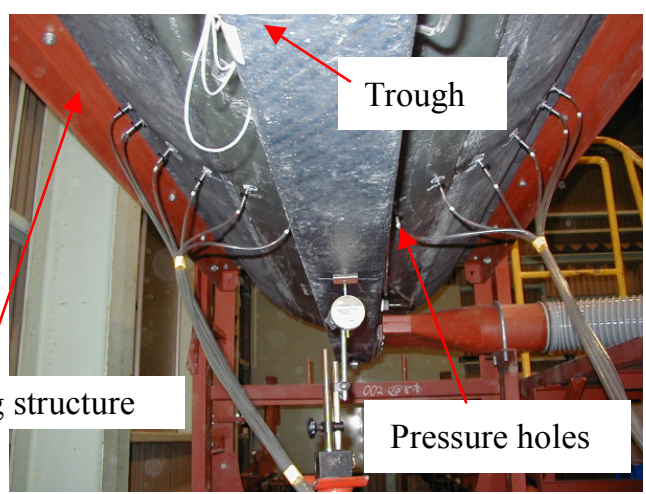

(b) Looking at FDC from underneath

Fig.3 Pictures of experimental apparatus

\subsection{Experimental Items and Purpose}

The experimental items and purposes are as follows:

(1) Obtaining of natural frequencies and their modes

(2) Obtaining of conditions for onset of the abnormal vibration

(3) Understanding the behavior of vibration and pressure at abnormal vibration

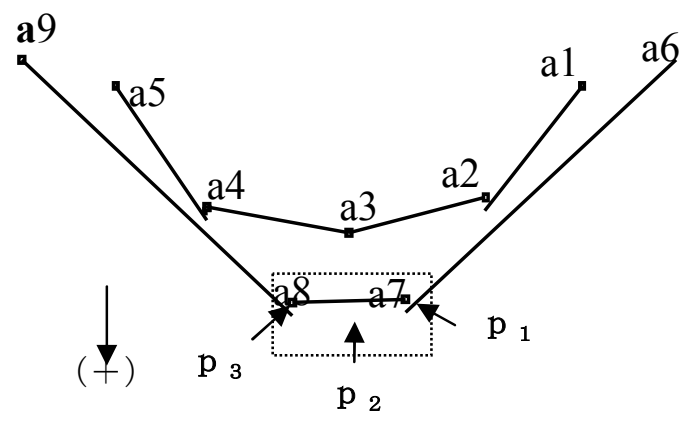

Fig.4 Measure points
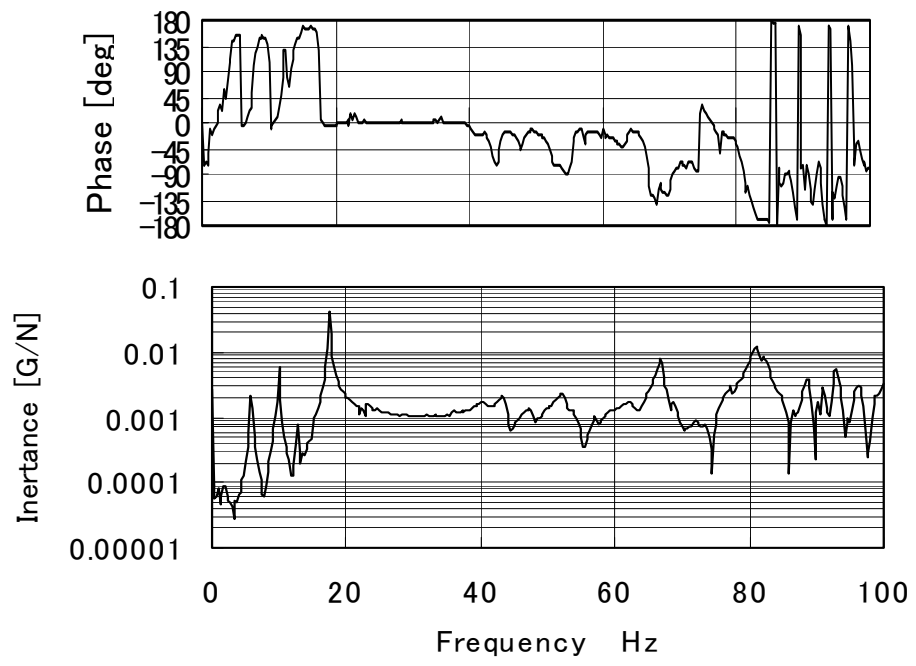

Fig.5 Inertance of trough 


\subsection{Measuring Items} That is,

The acceleration and the pressure at various points as shown in Fig.4 are measured.

(1) Accelerations of belt: 5 points $\left(a_{1} \sim a_{5}\right)$

(2) Accelerations of trough: 4 points $\left(a_{6} \sim a_{9}\right)$

(3) Pressure between belt and trough: 2 points $\left(p_{1}, p_{3}\right)$

(4) Pressure in air reservoir: 1 point $\left(p_{2}\right)$

Where the acceleration pickups are also attached to the belt as well as the trough and the acceleration is measured. Acceleration pickups and pressure gauges are attached at the center of longitudinal direction and specification of these pickups used here are as follows.

Acceleration: Product Company is RION Co. Ltd., Type is PV85, Frequency range is $1 \sim 7000 \mathrm{~Hz}$

Pressure Gauge: Product Company is KULITE, Type is XCS-128-093-5G, Resonance frequency is $100 \mathrm{kHz}$.

The pressure between the trough and the belt is measured by the pressure gauge attached to the tube which is $5 \mathrm{~cm}$ long and leads to the hole of $\phi 5$ set on the trough. As the measuring frequency range is below $100 \mathrm{~Hz}$, it is considered that the amplitude and the phase of pressure measured in this experiment are correct. Where the downward movement is positive and the higher pressure than the mean pressure is positive.

\section{Experimental Results and Discussions}

\subsection{Natural Frequencies of Trough and Supporting Structure}

Fig.5 shows one example of the inertance (acceleration per unit force) of the trough. This figure reveals that the natural frequencies of the first, the second, the third and the fourth modes of trough-supporting system are $5.75 \mathrm{~Hz}, 10.0 \mathrm{~Hz}, 12.75 \mathrm{~Hz}$ and $17.5 \mathrm{~Hz}$ respectively. Furthermore, each mode is shown in Fig.6. These modes are obtained by using the experimental modal software. To be concrete, two hundred points as shown in Fig. 2 are hit by the impulse hammer and the acceleration at the point " $\mathrm{A}$ " is measured. The characteristics of these modes are explained as follows:

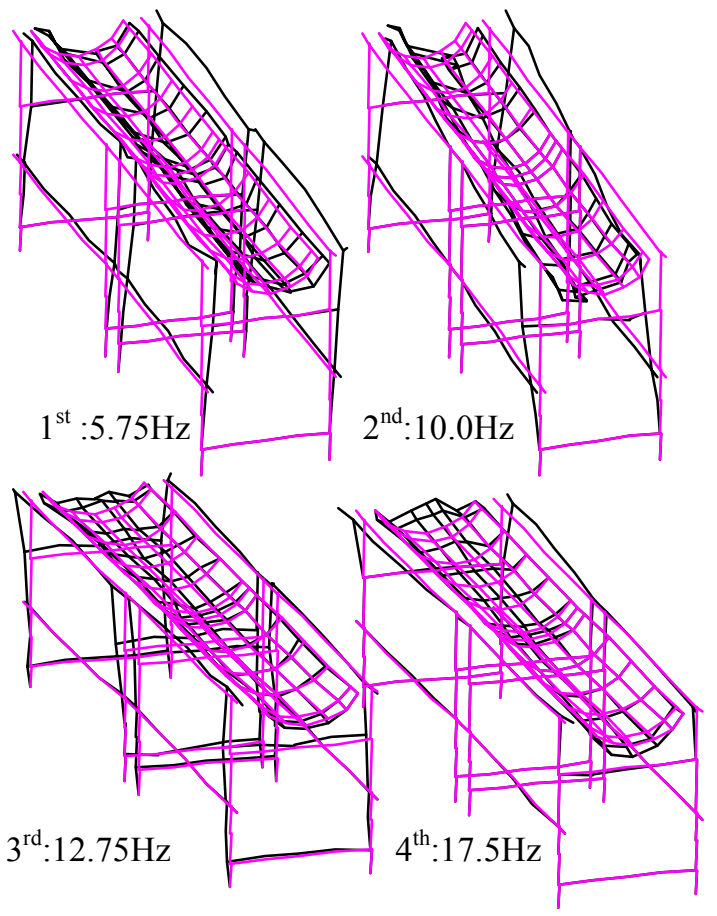

Fig.6 Modes of trough and frame 
The first mode : Both ends of the supporting structure move translation right and left in phase and the trough also moves by following it.

The second mode : Both ends of the supporting structure move yawing with the same phase and the trough also moves by following it.

The third mode : Both ends of the supporting structure move translation oppositely and the trough's ends move right and left oppositely and the trough center moves up and down.

The fourth mode : Both ends of the supporting structure move yawing oppositely, the trough's ends move right and left oppositely and the trough's center moves up and down.

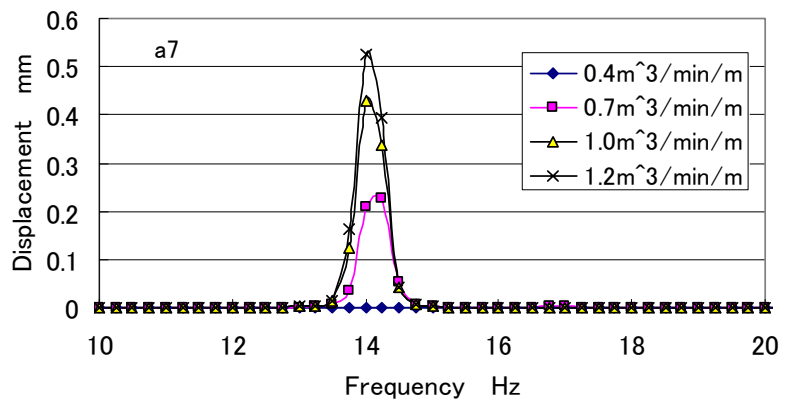

Fig.7 Spectra of displacement at a7

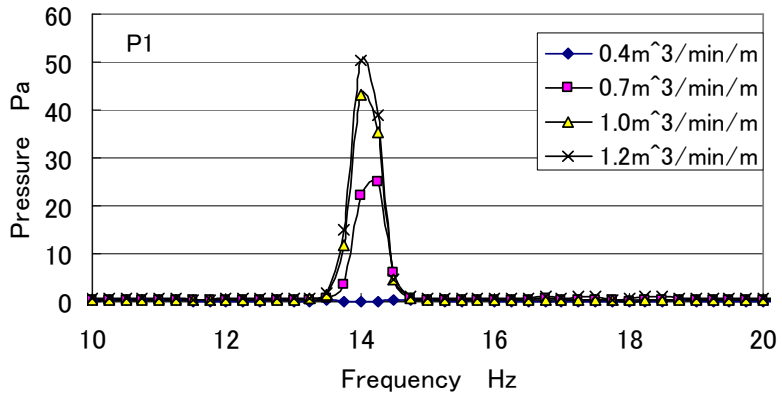

Fig.8 Spectra of pressure at p1

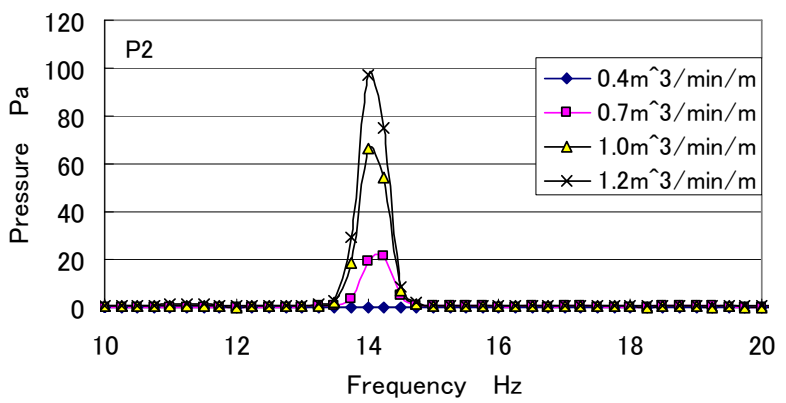

Fig.9 Spectra of pressure at p2

\subsection{Occurrence of Abnormal Vibration}

It is reasonable to evaluate whether the vibration is abnormal or not by the vibration of the trough, because the exciting force acting on the supporting structure is generated from the vibration of trough though the abnormal vibration can be perceived by the vibration of supporting structure

The vibration is defined as the abnormal vibration when the following conditions are satisfied.

(1) When the flow rate achieved critical value, the vibration becomes suddenly large.

(2) The vibration keeps constant or becomes larger when the flow rate increases. 
(3) The frequency of the abnormal vibration is the natural frequency of the vibration system.

Fig.7, Fig.8 and Fig.9 show the frequency analysis results of the displacement at the center of the trough (a7), the pressure between the trough and the belt (p1), and the pressure in the reservoir box (p2) respectively when the air flow rate is changed.

All of these spectra show the same tendency. Namely, the frequency of vibration is $14.3 \mathrm{~Hz}$ and the pressure between the trough and the belt $(\mathrm{p} 1)$ and the pressure in the reservoir box (p2) become large at the flow rate at which the vibration of trough is large.

The pressure $\mathrm{p} 1$ and the pressure $\mathrm{p} 2$ fluctuate with opposite phase as shown in Table 1 described after. Fig.10 and Fig.11 show the displacement (Center a7) and the frequency of the trough against the loads which are expressed by the percent of each load to the maximum load.

In Fig.11, the white symbols show the natural frequency and black symbols show the frequency corresponding to the maximum amplitude of vibrations.

From Fig. 10 and Fig.11, only the case of $\mathrm{W}=0 \%$ satisfies the condition of the occurrence of the abnormal vibration and it occurs over the flow rate per unit length $\mathrm{Q}=0.6 \mathrm{~m}^{3} / \mathrm{min} / \mathrm{m}$. The abnormal vibration does not occur for any other conditions.

The vibration (a7) at the occurrence of abnormal vibration becomes $520 \mu \mathrm{m}$ when $\mathrm{Q}=1.2 \mathrm{~m}^{3} / \mathrm{min} / \mathrm{m}$. The vibration is under $100 \mu \mathrm{m}$ with normal vibration. It is shown that the frequency of abnormal vibration is the natural frequency from Fig.11 (Refer to $\diamond, \diamond$ in Fig.11).

Fig. 12 shows the displacement of the belt end. It is small at $\mathrm{W}=0 \%$ and large at partial loads such as $\mathrm{W}=12.5 \%, 25 \%, 50 \%$. For example, the displacement of the belt becomes as large as $2000 \mu \mathrm{m}$ at $\mathrm{W}=25 \%$. On the contrary, the displacement of the trough becomes only $50 \mu \mathrm{m}$ at the same load as shown in Fig.10. From this fact, the vibration of the belt end is not the cause of the trough vibration.

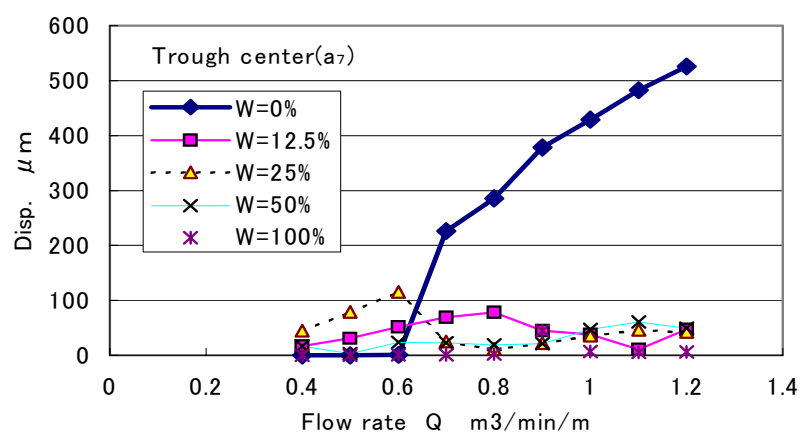

Fig.10 Displacement of trough

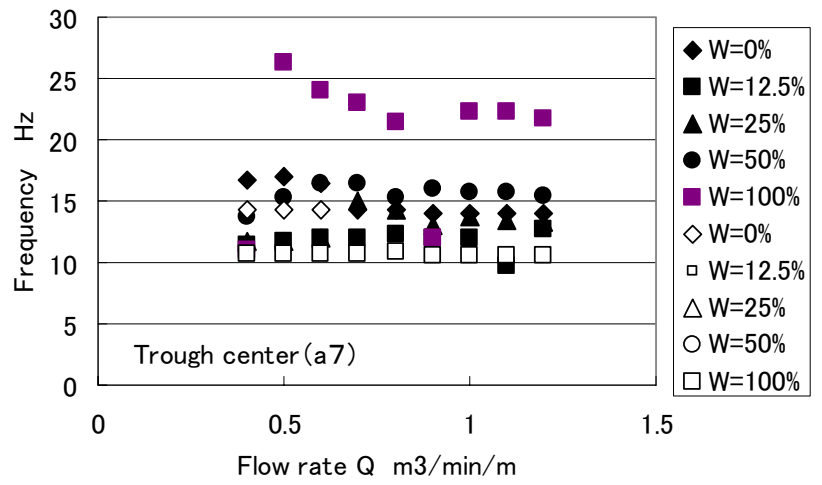

Fig.11 Trough vibration frequency 
Fig. 13 shows the pressure between the trough and the belt and it is the same as the belt vibration. This fact means that the belt vibration is due to the pressure fluctuation. Essentially, the abnormal vibration of this FDC is considered to be the self excited vibration due to the self movement in the two degrees of freedom system which consists of the belt-load system and the trough-supporting system. However the belt end is very flexible. So it is considered that the belt end is forced to vibrate by the pressure fluctuation.

\subsection{State of Vibration and Pressure at Abnormal Vibration}

Fig. 14 shows the state of vibration of the cross section of the trough at the condition of occurrence of abnormal vibration. That is, $\mathrm{W}=0 \%$ and $\mathrm{Q}=1.2 \mathrm{~m}^{3} / \mathrm{min} / \mathrm{m}$. Table 1 shows the measured results (amplitude and phase difference to the reference point a7) of the vibration displacement and the pressure at the condition described above, where the displacement $d$ is obtained from the measured acceleration by using the expression $d=a /(2$ $\pi \mathrm{f})^{2}$.

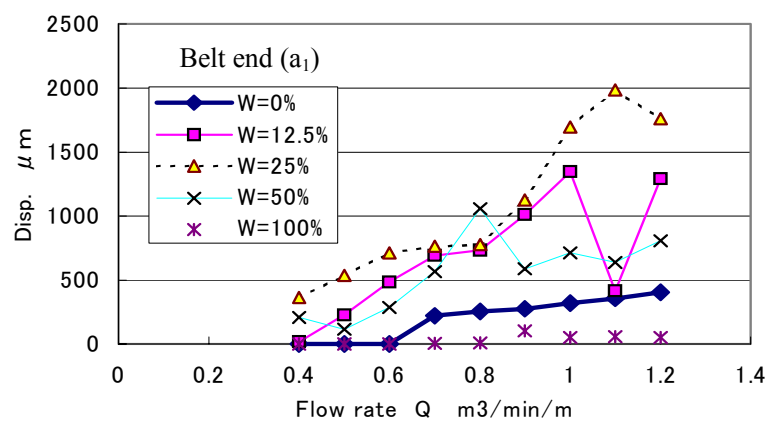

Fig.12 Displacement of belt end

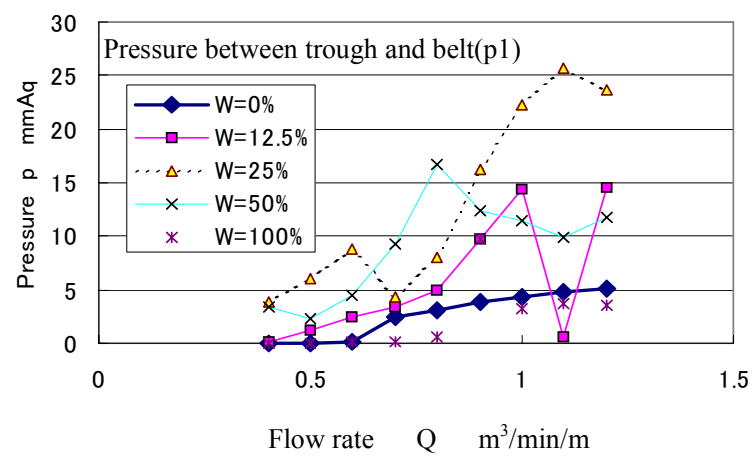

Fig.13 Pressure between trough and belt

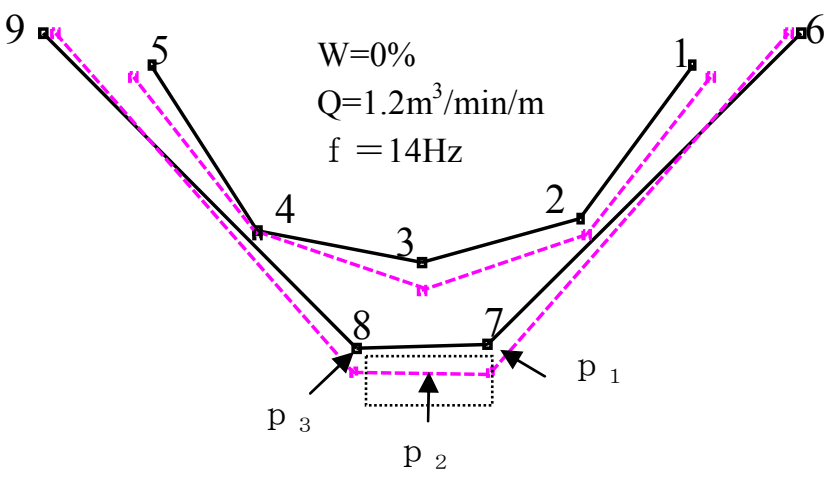

Fig.14 Vibration mode during abnormal vibration 
Table1. Measured values at $\mathrm{Q}=1.2 \mathrm{~m}^{3} / \mathrm{min} / \mathrm{m}$

\begin{tabular}{|c|c|c|}
\hline Measuring point & Amplitude & Phase Difference \\
\hline $\mathrm{a} 1$ & $539(\mu \mathrm{m})$ & -15.24 \\
\hline $\mathrm{a} 2$ & $585(\mu \mathrm{m})$ & 50.46 \\
\hline $\mathrm{a} 3$ & $595(\mu \mathrm{m})$ & -26.93 \\
\hline $\mathrm{a} 4$ & $322(\mu \mathrm{m})$ & 70.81 \\
\hline $\mathrm{a} 5$ & $564(\mu \mathrm{m})$ & 16.95 \\
\hline $\mathrm{a} 6$ & $294(\mu \mathrm{m})$ & -179.91 \\
\hline $\mathrm{a} 7$ & $527(\mu \mathrm{m})$ & 0 \\
\hline $\mathrm{a} 8$ & $476(\mu \mathrm{m})$ & -0.03 \\
\hline $\mathrm{a} 9$ & $342(\mu \mathrm{m})$ & 0.52 \\
\hline $\mathrm{p} 1$ & $50.36(\mathrm{~Pa})$ & -166.46 \\
\hline $\mathrm{p} 2$ & $97.11(\mathrm{~Pa})$ & 31.75 \\
\hline $\mathrm{p} 3$ & $48.69(\mathrm{~Pa})$ & -141.62 \\
\hline
\end{tabular}

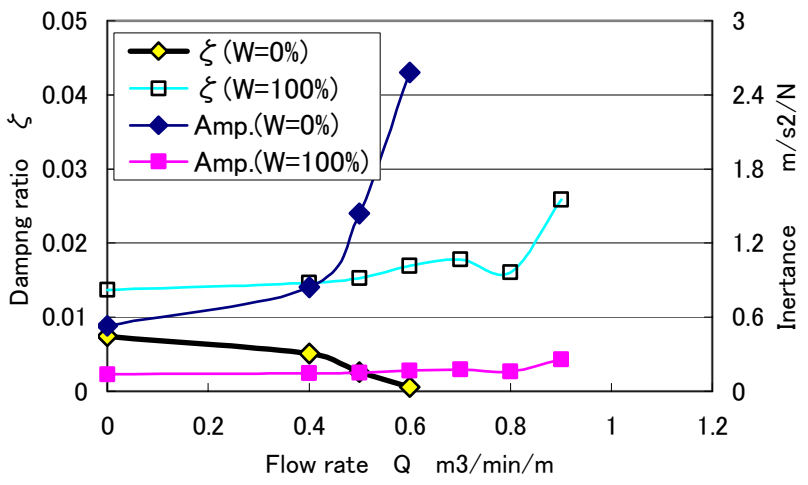

Fig.15 Damping ratio and amplitude vs. $Q$
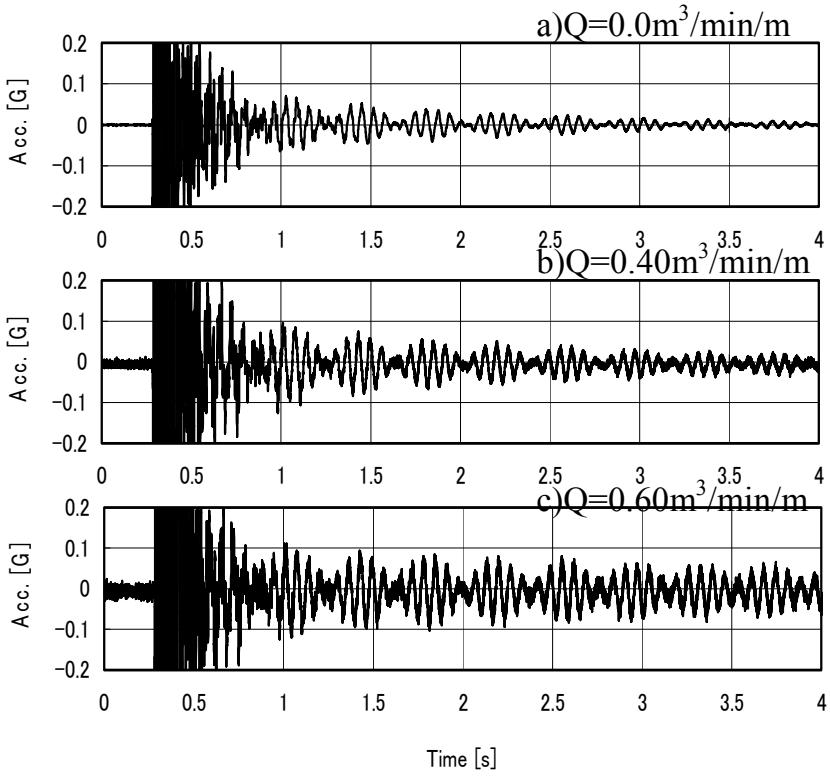

Fig.16 Vibration waves at each $Q(W=0 \%)$ 

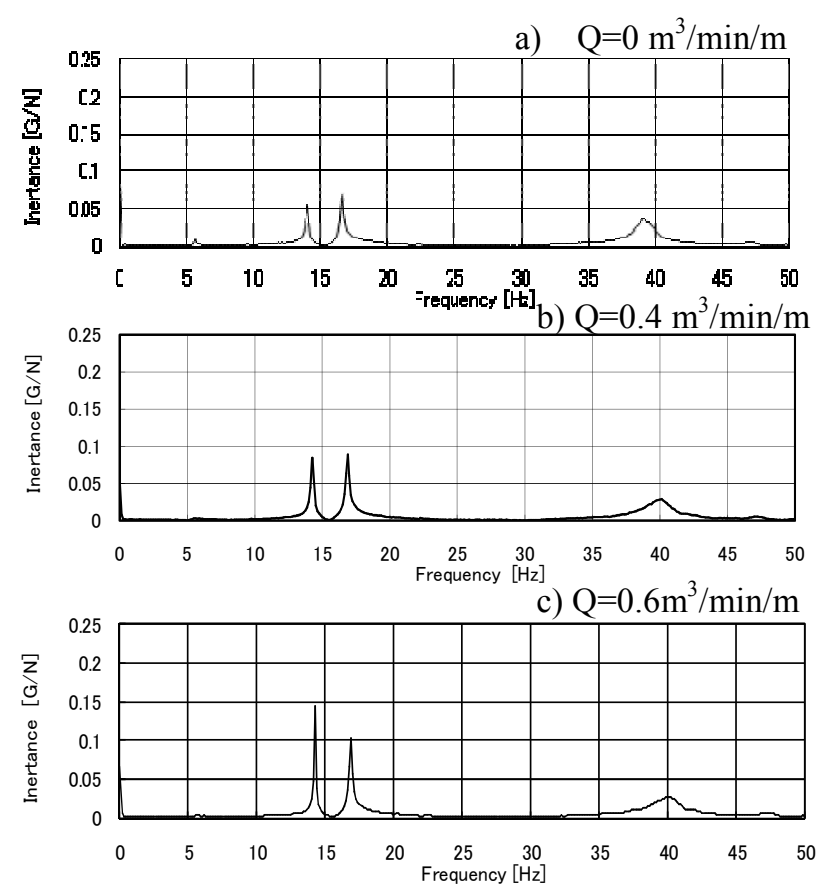

Fig.17 Spectra of vibration waves at each $Q(W=0 \%)$

The abnormal vibration mode corresponding to the 3rd mode in Fig.6 is that the both ends move right and left oppositely and the trough center moves up and down and the trough and the belt vibrate with the same phase. In this time, it is found that $\mathrm{p} 1$ and $\mathrm{p} 2$ are the opposite phase from Table1. The reason is considered as follows. Time derivative of channel width is small due to the same phase of the belt and the trough vibrations. Then the fluctuating flow rate flows into the channel and it makes the pressure p1 high. As a result, the pressure $\mathrm{p} 2$ becomes low due to decreasing the fluctuating flow rate in the reservoir.

Next, Fig. 15 shows the amplitude and the damping ratios at $\mathrm{W}=0 \%$ and $\mathrm{W}=100 \%$. These damping ratios were obtained by the half power method after frequency analyzing the time history shown in Fig.16. Fig.17 shows the frequency analyzing results of the time history shown in Fig.16. Two peaks can be seen in these figures because the time histories have beat phenomenon. The beat frequency coincides with the frequency deference of two peaks.

Close inspection from Fig. 15 reveals that the damping ratio decreases with increasing flow rate in the case of $\mathrm{W}=0 \%$ and it becomes negative when $\mathrm{Q}$ is greater than 0.6 $\mathrm{m}^{3} / \mathrm{min} / \mathrm{m}$. The negative damping means the occurrence of self-excited vibration, so it is possible to conclude that this phenomenon is the self-excited vibration. Fig.16 shows time histories of the trough vibration at $\mathrm{W}=0 \%$, in which a), b), and c) correspond to the cases of the flow rates are $0.0,0.4$ and $0.6 \mathrm{~m}^{3} / \mathrm{min} / \mathrm{m}$, respectively. These figures show that the damping becomes smaller as the flow rate increases.

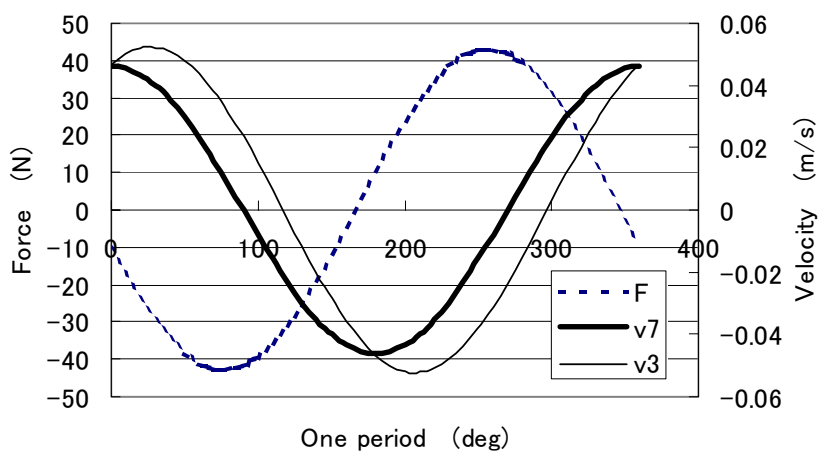

Fig.18 Relation between pressure and velocities $\left(Q=1.2 \mathrm{~m}^{3} / \mathrm{min} / \mathrm{m}\right)$ 
Moreover, the self-excited vibration is the phenomenon occurring by the mechanism generating the exciting force due to the self-vibration without external force. In the present study, it will be examined from the measured vibration and pressure data.

Fig. 18 shows the vibration velocities at measuring points of No.7 and No.3 and the pressure between the trough and the belt. These are expressed by $\mathrm{v}_{7}, \mathrm{v}_{3}$ and $\mathrm{F}$. Where the pressure between the trough and the belt is assumed to be uniform, because the phase of $\mathrm{p} 1$ and the phase of $\mathrm{p} 3$ are the same as shown in Table1. Then the force acting on the trough and the belt is given as $\mathrm{F}=\mathrm{p} \cdot \mathrm{S}$, where $\mathrm{S}$ is the pressurized area and is given as $0.85 \mathrm{~m}$ (Projected length) $\times 1 \mathrm{~m}$ (unit length). Therefore $\mathrm{F}$ roughly indicates the force per unit length. The energy per one cycle that the force gives to the vibration system is described as follows.

$$
W=\sum_{i=1}^{N} \oint F_{i}(t) \cdot v_{i}(t) d t
$$

Where $v_{i}(t) \stackrel{i=1}{1}$ is the velocity of the trough or the belt at the measuring point $i$ and $F_{i}(t)$ is the force which is the same directional component to the vibration in forces generated due to the pressure between the trough and the belt to the area represented by $v_{i}(t)$. Therefore the Eq. (1) is considered to be taken into account for the mode shape of the two dimensional model.

Here by considering that $\mathrm{a} 7$ and $\mathrm{a} 8$ are the same phase and the same amplitude, Eq. (1) is simplified as follows.

$$
W=\oint F(t) \cdot(v 7(t)-v 3(t)) d x=\frac{\pi}{\omega}|F| \cdot\left|v_{7}-v_{3}\right| \cos \theta
$$

The occurrence of the abnormal vibration can be judged by the sign of W. Namely, if W is a positive quantity, then the abnormal vibration occurs. On the contrary if $\mathrm{W}$ is a negative quantity, then it does not occur. Then the self exciting force generates when $-\pi / 2<\theta<\pi / 2$. Here $\theta$ is the angle made by the force vector $\mathbf{F}$ and the relative velocity vector $\mathbf{v}_{\mathbf{7}}-\mathbf{v}_{\mathbf{3}}$.

Fig.19 shows the relative velocity and the force waves of one cycle. The phase difference of the force to the relative velocity is 15 degrees, then the energy into the system becomes positive. This means that the self- exciting force exists.

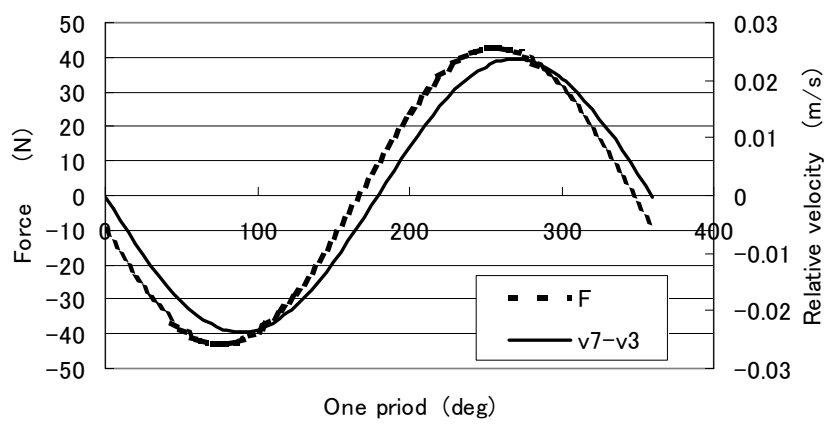

Fig.19 Relation between force and relative velocity $\left(Q=1.2 \mathrm{~m}^{3} / \mathrm{min} / \mathrm{m}\right)$

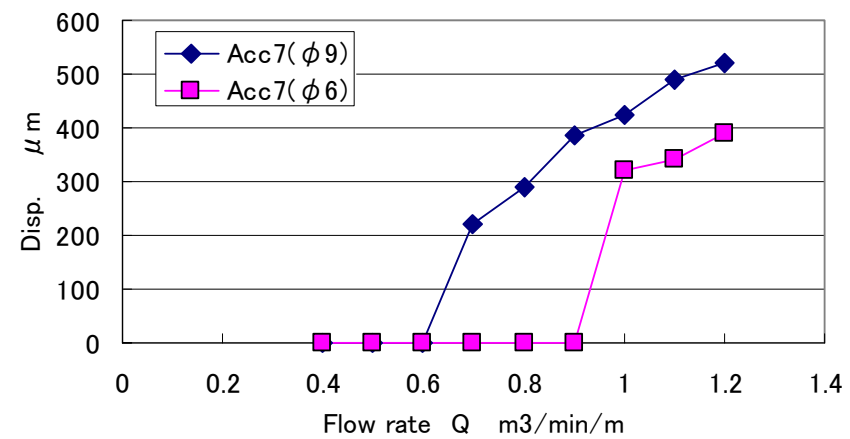

Fig.20 Comparison between before and after countermeasure 


\section{Countermeasures}

As a countermeasure, the diameter of a supplied smaller hole is used (from $\Phi 9$ to $\Phi$ 6). The result is shown in Fig.20. It can be seen that the threshold of occurrence of abnormal vibration varied from $0.6 \mathrm{~m}^{3} / \mathrm{min} / \mathrm{m}$ to $0.9 \mathrm{~m}^{3} / \mathrm{min} / \mathrm{m}$. This implies the improvement.

\section{Conclusions}

The vibration and the pressure were measured by using the actual partial model of the FDC in order to clarify the mechanism of abnormal vibration that sometimes occurs in the actual thing. The results are summarized as follows.

(1) The phenomenon that the vibration becomes large in the FDC is not the forced vibration but the self-excited vibration. The vibration mode of the trough at abnormal vibration is that both ends of the trough move right and left out of phase and the center of the trough moves up and down.

(2) Until now, the cause of abnormal vibration was thought to be the end part of belt hitting the trough. But its force is too small to give a large vibration to the trough from measuring data.

(3) To countermeasure this abnormal vibration, it is useful to make the air-supply hole smaller.

\section{References}

[1] Inada F. and Hayama S., "A Study on Leakage-Flow-Induced Vibrations ( $1^{\text {st }}$ Report, Fluid-Dynamic Forces Acting on the Walls of a One-Dimensional, Narrow, Tapered Passage)", Transaction of JSME, Vol.53, Vol.488, 1988, pp933-939

[2] Inada F. and Hayama S., "A Study on Leakage-Flow-Induced Vibrations ( $3^{\text {rd }}$ Report, Moment of Fluid-Dynamic Forces Acting on the Walls, One of which is Vibrating with Rotational Mode)", Transaction of JSME, Vol.54, Vol.507, 1988, pp.2565-2570

[3] Arai M. and Tajima K., "Leakage-Flow-Induced Vibrations of an Axisymmetric Body ( $1^{\text {st }}$ Report, Analysis of the Fluid Dynamic Forces Excited on an Axisymmetric Body)", Transaction of JSME, Vol.57, Vol.536, 1991, pp.1113-1121

[4] Dong-Wei LI, Kaneko S. and Hayama S., "A Study on the Annular Leakage-Flow-Induced Vibrations $\left(1^{\text {st }}\right.$ Report, Stability for Translational and Rotational Single-Degree-of-Freedom Systems)", Transaction of JSME, Vol.65, Vol.635, 1999, pp.2251-2256

[5] Dong-Wei LI, Kaneko S. and Hayama S.,"A Study on the Annular Leakage-Flow-Induced Vibrations (2nd Report, Stability Analysis and Experiments for Translational and Rotational Coupled Two-Degree-of-Freedom Systems)", Transaction of JSME, Vol.65, Vol.635, 1999, pp.2257-2262

[6] Oomori N. and Kobayashi M., "Stability Analysis of Flexible Belt floating on Air Flow", Paper of JSME, D\&D2000, No.342, CD

[7] Oomori N. and Kobayashi M., "Stability Analysis of Flexible Belt floating on Air Flow $\left(2^{\text {nd }}\right.$ Report, In case of Loading)", Paper of JSME, D\&D2000, No.342, CD 